\title{
Pedagogical Conditions Related to the Formation of Professional Value Orientations of Law Students
}

\author{
O. Vasylchenko, V. Vertegel*, V. Khrebtova, O. Murzina \\ Zaporizhzhia National University, Zaporizhzhia, Ukraine \\ *Corresponding author. E-mail: victoriavertegel@gmail.com
}

Paper received 05.12.20; Accepted for publication 16.12.20.

\section{https://doi.org/10.31174/SEND-HS2020-242VIII42-14}

\begin{abstract}
The article aims to examine the issue of the law students' professional values and their formation in the system of higher education particularly in the Ukrainian context. The authors analyze the term "value orientations" as an important component of the structure of the individual and define law students' professional value orientations and consider professional values' formation of future lawyers as their personal development in real processes of their education at university. Professional self-identification, selfrealization, and self-organization are defined as essential value orientations for future specialists.
\end{abstract}

Keywords: pedagogical condition, professional value orientations, professional self-identification, law students, value-forming component, academic material of value oriented character.

Introduction. The development of social and economic reforms in the context of modern concepts of education in the process of humanization and democratization of Ukrainian society puts forward fundamentally new requirements for valid criteria to evaluate the effectiveness and improve the professional training of future specialists. Therefore the function of scientific and methodological support of the system of professional training of specialists is a primary mission of the national system of higher education.

The focus of our study is precisely the training of future law students. The effectiveness of practical activities in the field of ensuring human rights and fundamental freedoms depend on the professional training of legal specialists. Today complex transformational processes are taking place in Ukraine, and this profession remains one of the most demanded.

Specificity of this profession determines the relevant inquiries for its subjects, in particular regarding their professional and personal development.

In this context modern scientific approaches determine the main values and value orientations of the individual, consider them as his/her personal development, which can be expanded, refined, specified in real processes of education and self-education. Therefore, the problem of creating professional value orientations of law students is of particular importance. The creation of necessary and sufficient educational conditions of formation of professional value orientations becomes crucial in the process of law students' training.

The scientific analysis of the problem of formation of professional value orientations of law students during professional training involves the definition of a number of pedagogical conditions that enable to create effectively the process of formation of professional value orientations.

The purpose of the article is to identify and justify effectiveness of the pedagogical conditions of forming law students' professional value orientations.

In order to solve the problem the methods of analysis of scientific works, content of academic disciplines, observation, and students' interviews were used.

Research. Scientists A. Aleksyuk, A. Ayrzanain, P. Pidkasystiy determine pedagogical conditions as factors that influence the process of achieving the goal and they divide them in two groups: external (positive relations between the lecturer and the student; objective assessment of the educational process; place of study, classrooms, climate) and internal or individual (students' individual characteristics - state of health, qualities of character, experience, abilities, skills, motivation and etc) [10].

A Ukrainian researcher O. Brazhnych defines pedagogical conditions as a set of objective possibilities of content, methods, organizational forms and material possibilities for the implementation of the educational process, which ensures the successful achievement of the goal [3].

Professor V.Andreev believes that the pedagogical conditions is the result of "purposeful choice, development and application of the elements of content, methods (techniques), as well as organizational forms of learning to achieve... goals" [1, p. 124].

The next definition of pedagogical conditions is presented as a component of the educational process including special courses, necessary legal framework, the preparedness of the teaching staff, the optimal combination of traditional and nontraditional forms and methods of teaching, monitoring of the effectiveness of the process of the formation of the studied phenomenon, the creation of the appropriate organizational and educational structure, the didactic equipment of the educational process [11].

The most relevant for our study is the interpretation of pedagogical conditions made by V. Stasyuk who defines them as a set of external circumstances where the holistic educational process of professional training of specialists is depended on them and takes place with the activity of an individual or a group of people [17, p. 16].

The issue of value orientations has been always in the focus of scientists since there is always an attempt to understand what make people behave differently in different situations and what values are universal ones. From the psychological point of view one of the influential studies of value orientations is known as Kluckhohn-Strodtbeck Value Orientations theory. Later it was analyzed by Hills who added his interpretation in the form of questions and answers [5].

Among proposed him questions we would like to stress those which are crucial for our research because they deal 
with the person's motivation to work. The scientist has risen such questions as whether it is a contribution to society, personal development or earnings [5, p.10].

Professional value orientations occupy one of the leading places in the system of value orientations and their formation is the most important condition for the personal development and professional self-determination of a young person [2].

The next notion to analyse is the professional values of a future lawyer. According to T. Kalyuzhna the structure of value orientations of a modern lawyer includes three subsystems: 1) cognitive - value ideas of a person; knowledge of objects, phenomena, processes, worldview; 2) emotional - a persistent person's feeling to objects; emotional and valuable relation to the world, connections, emotions, assessments; 3 ) active - a tendency to a certain type of social behaviour, methods and techniques of interconnection, ways of achieving (realization) of life plans [8].

In the context of finding out the basic professional values that are needed for future lawyers, we have taken into account values determined in the legal practice by Robert MacCrate. Among these values are: professional selfimprovement, responsibility, a strong desire to promote justice, morality [9].

Besides, we are sure that law students' professional values should be grounded on the main principles of the "Code of Professional Ethics of a Lawyer" [16].

These main principles are in the content of the code of lawyer's professional practice and consist of:

- a humane attitude towards people as an integral principle of the code of the lawyer's professional ethics;

- the rule of law that means the lawyer's awareness of his/her mission of adherence to the law, observance of the law.

Thus, in our opinion, the professional value orientations of law students, in the context of our research, should include the following:

- professional self-identification, positive attitude to the profession, recognition of the importance of special knowledge and skills for further use in future professional activity;

- self-realization, self-improvement, recognition of the need for professional growth to achieve personal and professional development;

- self-organization, self-education and self-diagnosis, desire to apply the acquired skills in future professional activities.

Definition of the essence of professional value orientations of law students, as well as the analysis of the pedagogical conditions, allowed us to determine the following pedagogical conditions of the formation of law students' professional value orientations:

- stimulation of professional self-identification of law students through demonstration of exemplary patterns of professional behaviour and thinking of successful professionals in the sphere of jurisprudence, awareness of the importance of professional values by students;

- filling the content of certain educational disciplines with value-forming component and ensuring its assimilation and support with means of objective diagnostics, as well as the development and use of additional professional educational programs for the formation of professional value orientations;

- introduction of modern forms of teaching and optimization of classroom and extracurricular educational interaction of participants in the educational process through the creation of the informational and learning environment and its enrichment with interactive and contextual methods.

Hence, we can describe the first pedagogical condition as a stimulation of professional self-identification of law students through demonstration of exemplary patterns of professional behaviour and thinking of successful professionals in the sphere of jurisprudence, awareness of the importance of professional values by students.

Studying the psychological foundations of the formation of professional self-identification of law students, a Ukrainian scientist R. Kalamazh emphasized the specific of the content of this important construct of "I-concept" of future specialists, which is connected with the peculiarities of the profession chosen by them. According to her understanding, the professional "I-concept" of law students is a complex formulation that includes personal and professional values, personal and professional qualities, as well as professional knowledge and skills. She believes that professional selfidentification of a future specialist is the main factor in his/her professional self-determination, self-evaluation and development [7].

The leading role is played by the psychological mechanisms of self-education, which consist of the creation in the imagination the gradual implementation of the image of the "the present of me" in the direction of the image of "the future of me" which results in the formation of the person's ability to predict consciously the future, to foresee it, to imagine yourself in the future. In this case it is crucial for future specialist to set priorities, goals and to understand his/her weaknesses and strengths in their professional preparation framework. Great attention is paid to the imagination and description of the images of the desired future, primarily because images as psychological formation have a significant impact on law students' behaviour.

Hence, one of the ways to promote law-students' professional self-identification we see in the involving media to form positive images of professionals in law practice.

Thus, resources of mass media, Internet, social networks become not only a demonstration material, a world of ideas and values for modern youth, as they present typical situations of social interaction, but teaching/learning material for future lawyers. That is why we consider necessity to use review of feature and documentary video with demonstration patterns of behaviour of professionals of law practice while they execute their duties and solve problems at workplace. In order to broaden the students' outlook, the variability of the learning material and the provision of the most interesting information, we propose to organize meetings, interviews with prominent judges, attorneys, notaries, lawyers.

In addition, we offer future specialists to attend public lectures, conferences, seminars, round tables, workshops, museums, exhibitions. Besides, participation in legal clinics and internships, which enables students to comprehend and consolidate existing and new information and get a 
sample of masterful performance of professional activity, is another one of the most effective forms of formation law students' value orientation.

The second pedagogical condition is filling the content of certain educational disciplines with value-forming component and ensuring its assimilation and support with means of objective diagnostics, as well as the development and use of additional professional educational programs for the formation of professional value orientations.

Formation of professional value orientations of future lawyers in the classroom requires updating not only its forms, but also the content of legal education. Since, the process of formation of studied phenomenon is considered by us in a holistic manner, then the content of all academic disciplines should be oriented towards the formation of future lawyers' professional value orientations. In this case, we define interdisciplinary connections as a crucial factor in the context of the second pedagogical condition. These connections of disciplines of the humanities, socio-economic, natural sciences, professional and practical training are directed at enhancing students' awareness of the learning content in the context of the future profession and promote the formation of future lawyers' professional value orientations.

Seeing that, the process of formation of professional value orientations involves the mechanism of selfimprovement, self-development, self-education of the individual. We propose to update the content of legal education through the inclusion of value-forming component to the content of academic disciplines of $\mathrm{Hu}-$ manities, as well as the deepening psychological and pedagogical training of future lawyers.

So the formation of future lawyers' professional value orientations requires a holistic approach both to the personality and the educational process. For this reason a lecture as a form of educational process should be supplemented by a system of seminars and practical classes, which are organized as discussions, debates, brain rings, round tables, colloquiums.

At the seminars and practical classes, microsituationsproblems and situations-illustrations are modeled to convince future lawyers of importance or probability of one or another theoretical thesis of a lecture. The task of the situation-illustration is to suggest students to analyze it and make a well-founded legal decision.

Among the forms of work at the seminars the preference is given to discussions that encouraged future lawyers to develop their skills of professional reflection and initiative in solving professionally oriented tasks.

Consequently, the process of forming future lawyers' skills and competences for the assimilation of professional values begins with the process of mastering the disciplines at the university.

To achieve this goal it is necessary to involve modeling the educational process with the substantive and social content of the future professional activity of students integrating the value-forming component not only into the content of such subjects as "Legal Conflict Management", "Legal Deontology", "Legal Psychology", but also into the content of "Foreign Language for Specific Purposes". It should be mentioned that foreign language is paid great attention in the system of higher education nowadays.
Besides, knowledge of a foreign language is identified as one of the key competences of the Council of Europe in education: "Learning languages and being able to communicate in more than one language remains one of the key competences" [4].

In the context of this pedagogical condition we distinguish individual, paired, group and collective forms that contribute to the formation of professional value orientations of students of legal professions.

Methods of educational influence on students used in their learning subjects are methods, that affect consciousness, aimed at the formation of views, ideas, concepts; active methods that stimulate self-esteem, selfreflection, self-education (modeling, solving professional situations, conversations, exercises).

In order to implement the value-forming component in the educational process, materials of documentary, scientific or artistic texts reflecting social, moral, cultural and valuable factors and features of the legal profession are used as well as revealing the main features of professional activity.

Speaking of university subjects we point out that the academic discipline "Foreign Language for Specific Purposes" as a subject of Humanities has a great potential and tools for the formation of law students' professional value orientations.

Besides, the use of foreign language in this context is defined by the possibility of selecting a wide range of academic material of value oriented character. It gives students possibility to find out foreign outstanding practices in the the field of law and to compare them with the Ukrainian law practice.

Thus, the academic material of value oriented character in foreign languages is successfully used while teaching Foreign Language for Specific Purposes to law students. It can be presented in writing, audio or visual forms of works of fiction or journalism, documentary and feature films, videos of prominent lawyers and vivid trials containing examples of the lawyer's professional behavior in various situations. Such learning material promotes students' positive attitude towards the profession, recognizing the need to achieve personal and professional development and encourages them s to apply their skills in further legal activity.

Thus, the developed pedagogical condition promotes future lawyers to be aware of the fact that the choice of profession obliges him/her to become a carrier, creator and distributor of humanistic values and be a defender of justice and human rights contributing to the development of the moral culture of society. Moral culture implies an ethical component that imposes moral requirements for the personality of a specialist. The formation of a professional lawyer's culture involves the unity of the process of creating professional ethical values and their application [6].

To form professional value orientations effectively during the lessons we suggest implementing business and role-playing games. It is also possible to conduct a briefing in the form of an expanded conversation, or small reports with the following discussion.

These methods facilitate the students' exchange of ideas, their debates. During the lessons it is important to observe a positive, friendly atmosphere between all partici- 
pants of the educational process. Therefore, it needs the teacher to establish respectful communication and be able to involve students in the discussion of real life situations. Law students should be encouraged to work on their professional self-development by learning effective ways of communication in their further workplace. These skills will help future specialists to eliminate misunderstanding during their professional activity and be respectful to the clients.

Within the framework of the developed pedagogical condition, the course "Formation of Professional Values Orientations of Future Lawyers" is proposed. It provides the expansion and deepening law students' knowledge in the field of professional self-identification and students are motivated to work on:

- their self-organization that is to train future specialists to formulate their goals in further professional activity;

- creating an individual strategy of professional selfimprovement;

- the development of their desire to improve personal and professional skills;

- the development of their self-diagnostic skills.

The content of the course includes combination of active and interactive training (situations review, learning through play, completion of creative tasks, role-playing games, testing and self-testing, analysis of visual material, etc.) and a theoretical material aimed at mastering future lawyers' knowledge.

Thus, for example, one of the role-playing games is "Who will win?" Students are proposed to work in 3 groups: "law-abiding people", "socially responsible people" and "people who are hesitant about social or legal responsibility". They prepare reports on professionally oriented topic. The winning team is that team that convinces "people who are hesitant about social or legal responsibility" to take their arguments. In this case students are taught to take responsibility before a society, develop professional communicative skills and express their ideas. We are sure that such tasks stimulate law students' selfimprovement, self-reflection and desire to apply the acquired skills in their future professional activitiy.

To indentify the specifics of the professional value orientations of the students we use the method developed by O. Rudenko "Square of Values" [13]. It makes it possible to divide value orientations into the following groups: status, those that related to the content of labor, socially significant, working conditions, self-affirmation, personality development, work outcome. We also monitor the process of formation of professional value orientations using the objective diagnostics such as Edgar Schein's "Career Anchor" (a combination of perceived areas of competence, motives, and values relating to professional work choices) [15], Milton Rokeach value survey (RVS) [12] and "The Sentence Completion Test" developed by Dr. Joseph M. Sacks and Dr. Sidney Levy [14].

The Sacks sentence completion test typically provides respondents with the beginnings of sentences, referred to as stems; and respondents then complete the sentences in ways that are meaningful to them. So, our students are proposed to complete sentences that reflect their attitude towards professional values: "I see my future as...", "I chose my profession because...", "I think as a future specialist I can..." and so on.
Taking into consideration the value-forming component of the educational disciplines' content and in order to increase the efficiency of professional training of future lawyers we need to improve the existing teaching methods and search for the new ones. That is why we propose to use complexes of technical and didactic means that ensure the interconnection of classroom and extracurricular forms of training.

Thus, the next pedagogical condition for the formation of value orientations of law students is the inroduction of modern forms of teaching and optimization of classroom and extracurricular interaction of participants of the educational process through the creation of the informational and learning environment and its enrichement with interactive and contextual methods.

Various methods of interactive learning can be widely used on training the law students in order to achieve this goal. In our opinion, business role-playing games of a professional nature (legal advices, court hearings, parliamentary debates, interrogation or examination, etc) are definitely effective ones. They enable students not only to develop the skills of unrehearsed oral speech, but also to have a direct impact on intellectual and professional development, teach them to notice the various nuances of professional interaction, reasonably express and defend their point of view, gain skills of professional communication, that is to assimilate professional values.

Analyzing the pedagogical condition mentioned above it is worth pointing out the importance of such modern teaching methods and technologies as case study, role play, simulation, think-tank, video-training etc.

We believe that the case study method is especially efficient while teaching law students because it is oriented to developping of such important qualities as analytics, critical thinking, creativity, flexibility in problem solving. The essence of such a method is to use specific cases (situations, stories, texts which are called "case") for joint analysis, discussion and decision making from a certain section of discipline. The method develops practical thinking skills for future administrators, lawyers and project leaders, and greatly differs from traditional methods of teaching.

At the same time the case study method encourages students' cognitive interest in academic disciplines and fosters the development of their research, communicative and creative skills. Besides, its specificity is to create a problem situation based on real life facts that helps law students to understand the necessity of professional selfimprovement, the importance of obtaining and applying special knowledge and skills for further use in their future legal activities.

So the use of modern educational software in the professional training of law students in order to form their value orientations makes learning more successful, since it allows both students and teachers to spend time more effectively while accomplishing the task and it stimulates the formation of such students' value orientations as selforganization, self-education and self-improvement.

Conclusions and Discussion. Formation of future lawyers' professional values orientations is realized through stimulation of professional self-identification of law students, filling the content of certain educational 
disciplines with value-forming component, introduction of modern forms of teaching, interactive contextual methods and optimization of classroom and extracurricular interaction of participants in the educational process.

Therefore, in the process of professional training of future lawyers, there was gradual transition from students' educational activity to professional one. The developed pedagogical conditions allow to stimulate formation of future lawyers' professional value orientations and at the same time to increase the students' motivation to study, raise their internal cognitive, effective, conscious motives that would affect all types of future lawyers' activities.
The information and educational environment contributes to the increase of the effectiveness of learning due to students' educational activity, their regular independent work with the use of modern software and technical means. The result of such training is the formation of the personality of the future lawyer with the necessary set of formed value orientations who is able to solve effectively various professional problems.

The prospects of our research we see in the analysis and selecting specific methods to engage future lawyers in more deepen professionally oriented situations.

\section{REFERENCES}

1. Andreev, V. I. Pedagogy: Educational Course for Creative Self-Development (3rd Ed). Kazan: Center for Innovative Technologies, 2012. -608 p.

2. Bekh, I. D. Education of a Personality. Kyiv: Lybid, $2008-$ $848 \mathrm{p}$.

3. Brazhnych, O. G. Pedagogical Conditions of Differentiated Teaching of Pupils of a Secondary School: Ph. D. Disertation, Kryviy Rih, 2001. - 238 p.

4. Council of the European Union. Key Competence for Life Learning. Recommendation. 2018. https://eurlex.europa.eu/legalcontent/EN/TXT/PDF/?uri=CELEX...from=EN

5. Hills, M. D. (2002). Kluckhohn and Strodtbeck's Values Orientation Theory. Online Readings in Psychology and Culture, 4(4). https://doi.org/10.9707/2307-0919.1040

6. Ivanova, Yu. Yu. Formation of Value Orientations of Students - Future Social Teachers. Native School, No. 7, pp. 14-17, 2011. http://nbuv.gov.ua/UJRN/rsh_2011_7_5.

7. Kalamazh, R. V. Model of Professional I-Concept of Future Lawyers. Scientific Papers of the National University of Ostroh Academy: Psychology and Pedagogy (Vol. 16, pp. 8593. 2010. http://nbuv.gov.ua/UJRN/Nznuoapp_2010_16_11.

8. Kalyuzhna, T. G. Pedagogical Axiology in the Conditions of Modernization of Professional and Pedagogical Education. Kyiv: National Pedagogical University named after M. P. Dragomanov. 2012- 212 p.

9. Mac Crate, R. Professional Values in the Practice of Law.
William Mitchell Law Review (Vol. 27, Iss. 2, Art. 41), 2000. http://open.mitchellhamline.edu/wmlr/vol27/iss2/41

10. Organization of Independent Work of Students in the Conditions of Intensification of Education / [Aleksyuk, A. M.; Ayurzanain, A. A.; Pidkasystiy, P. I. \& others]. - K: ISDO, 1993. - $336 \mathrm{p}$.

11. Pavlyutenkov, Ye. M. Modeling in the System of Education (in diagrams and tables). - Kharkiv: Osnova, 2008. Is. 7 (67), $128 \mathrm{p}$.

12. Rokeach, M. The Nature of Human Values. New York: Free Press, $1973-438$ p.

13. Rudenko, O. A. Formation of Professional Value Orientations of Students - Future Professionals in the Sphere of Entrepreneurial Activity. Zaporizhzhia: Zaporizhzhia Regional Institute of Postgraduate Education, 1997 - p.

14. Sacks, J. M. \& Levy, S. The Sentence Completion Test. In L. E. Abt \& L. Bellak (Eds.), Projective Psychology: Clinical Approaches to the Total Personality. New York: Alfred A. Knopf., $1950-485$ p.

15. Schein, E. \& Van Maanen, J. Career Anchors: The Changing Nature of Careers Self Assessment (4th Ed). New York: John Wiley \& Sons Inc, $2013-24$ p.

16. Skakun, O. F. \& Ovcharenko, N. I. Legal Deontology. Kharkiv: Osnova, $1999-280$ p.

17. Stasyuk, V. D. Economics from A to Z to Senior Pupils and Students. Odessa: South Ukrainian State Pedagogical University named after K. D. Ushynsky.2003, - 208 p. 